Florida State University College of Law

Scholarship Repository

Scholarly Publications

7-2012

\title{
Fundraising and Optimal Policy Rules
}

Murat C. Mungan

Bariş K. Yörük

Follow this and additional works at: https://ir.law.fsu.edu/articles

Part of the Law and Economics Commons

\section{Recommended Citation}

Murat C. Mungan and Bariş K. Yörük, Fundraising and Optimal Policy Rules, 14 J. PUB. ECON. THEORY 625 (2012),

Available at: https://ir.law.fsu.edu/articles/119

This Article is brought to you for free and open access by Scholarship Repository. It has been accepted for inclusion in Scholarly Publications by an authorized administrator of Scholarship Repository. For more information, please contact efarrell@law.fsu.edu. 


\title{
Fundraising and optimal policy rules*
}

\author{
Murat Mungan ${ }^{\dagger} a n d$ Barış K. Yörük ${ }^{\ddagger}$ \\ Accepted Recently (on Nov 02 2010) \\ Journal of Public Economic Theory
}

\begin{abstract}
This paper develops a simple spatial model of fundraising, in which charities select a target population to solicit donations. First, we show that in a competitive charity market without any intervention, the number of charities in the market and/or the overall net funds raised by charities may be sub-optimal. Next, we analyze whether a social planner can prevent such shortcomings and show that a regulatory mechanism can be designed to achieve socially desirable outcomes. In contrast to the previous literature, our model does not necessarily produce monopoly as the optimal market structure. We show that if fixed costs associated with establishing charities are sufficiently low, then the optimal market structure is not a monopoly. Given the importance of the trade-off between the volume and variety of charitable services, we argue that this result may be of particular interest to policy makers.
\end{abstract}

Keywords: fundraising, social planner, regulatory policy

JEL classification: H21, L31, L38

\section{Introduction}

Each year, people contribute billions of dollars to a wide range of charitable organizations. Estimates are that in 2006 over $\$ 200$ billion was given by individuals to charitable causes. Individual giving has also been increasing over time. On average, people gave approximately $1.5 \%$ of their income to charities in 1995, whereas this amount has risen to $2.1 \%$ in $2001 .{ }^{1}$ As individual giving has increased over time, fundraising has evolved into a highly professional industry, resulting in thousands

\footnotetext{
${ }^{*}$ We thank Hideo Konishi, Larry Kranich, Tayfun Sönmez, and Richard Tresch for their helpful discussions and comments. All errors remain ours.

${ }^{\dagger}$ Boston College, Department of Economics and George Mason University, Law School. E-mail: mungan@bc.edu.

${ }^{\ddagger}$ University at Albany, SUNY, Department of Economics. E-mail: byoruk@albany.edu.

${ }^{1}$ Source: Giving USA, 2003. See, Andreoni (2006a) for further discussion and detailed figures.
} 
of charitable organizations hiring professional fundraising staff and spending considerable amounts of money in fundraising activities each year.

These facts raise several important policy questions. First, what role do fundraisers play in affecting the amount of charitable gifts received? Although the existing literature does not focus much on the effect of fundraising on charitable giving, recent empirical research has shown that fundraising plays a vital role in increasing both the propensity to give and the level of contributions. For example, using data drawn from tax returns of charitable organizations, Khanna et al. (1995) and Okten and Weisbrod (2000) show that there is a positive relationship between fundraising expenses and total charitable contributions. A similar relationship is also found by Schervish and Havens (1997) and Yörük (2009) using household level survey data.

Given the importance of fundraising, another relevant question is how much money should charities allocate on fundraising expenses? Recently, many charities have been criticized for spending too much of their resources on fundraising. The focus on fundraising costs has become so intense that many charity evaluators and potential donors tend to view the level of such costs as the principal characteristic to take into account in estimating the quality of charitable organizations. The evidence suggests that the concerns on excessive fundraising expenses are legitimate. Recent IRS data on charitable organizations show that on average charities spend around $18 \%$ of total contributions in fundraising expenses whereas the widely accepted standard among professional fundraisers is $10 \%{ }^{2}$ Furthermore, estimates from the empirical studies show that many charitable organizations spend too much money on fundraising expenses. For example, Jacobs and Marudas (2006) investigate 76 non-profit organizations and find that among them 24 engaged in excessive fundraising. Okten and Weisbrod (2000) report that the ratio between fundraising expenditures and private donations averages $15 \%$ for different types of charitable organizations. It is also well-documented in the theoretical literature that competition among charities may result in excessive fundraising costs. ${ }^{3}$

In light of these findings, what regulatory policies can a policy maker use to eliminate excessive fundraising expenses? A widely discussed policy in the literature is to impose a monopoly united charity and regulate entry into the market. ${ }^{4}$ This policy helps to economize on fundraising costs by reducing competition for donations among member charities. Although this policy seems to be effective, it also has an obvious shortcoming. It sacrifices diversity among charities. However, promoting a variety of charitable services may be desirable since specialization in a competitive charity

\footnotetext{
${ }^{2}$ See, for example, Bradley, Jansen, and Silverman (2003).

${ }^{3}$ See, for example, Rose-Ackerman (1982) and Economides and Rose-Ackerman (1993).

${ }^{4}$ Rose-Ackerman (1982) discusses the pros and cons of the united monopoly charities.
} 
market encourages people to contribute to charities that provide their favorite charitable services. ${ }^{5}$ Therefore, while maximizing overall contributions, an ideal policy should also allow for ideological diversity among charities. ${ }^{6}$

Since Rose-Ackerman (1982) has introduced the first formal theoretical model of fundraising, several others have attempted to model charitable organizations as strategic players. Most of the theoretical literature has focused on the effect of various fundraising techniques on the amount of contributions received, ${ }^{7}$ while only a handful of studies have examined undesirable effects of competition among charities and relevant policy solutions. The main conclusion of the papers that focus on competitive charity markets is that diversification of charities does not produce optimal results even when people have widely varying tastes for charitable services. This paper builds on this result. We develop a simple spatial model of fundraising in which charities with different ideologies select a target population to solicit donations. We refer to this interaction among charities as the solicitation game. In contrast to the previous studies, we assume that charitable solicitations are noisy signals that inform the potential donor about the ideology of the charity. ${ }^{8}$ Using these signals, donors contribute to the charity that they believe is the closest to their ideology. We analyze the equilibrium properties of the solicitation game and show that competition among charities may not produce socially optimal results in a market without any intervention. ${ }^{9}$ In particular, competition may yield a sub-optimal level of overall contributions relative to the cost of fundraising. If the cost of fundraising is sufficiently low, then some donors are solicited by multiple charities which leads to excessive fundraising costs. In contrast, if the fundraising costs are sufficiently high, then a sub-optimal number of charities may enter the market. Furthermore, we recognize the trade-off between the variety and volume of charitable services as an important policy problem. We show that the optimal market structure depends only on the natural costs of fundraising such as the fixed costs of establishing a charity and soliciting donations. If these costs are sufficiently low, then the optimal market structure is not a monopoly.

\footnotetext{
${ }^{5}$ A monopoly united charity may not be desirable for charities as well, since they may also dislike the monitoring of their activities (Chua and Wong, 2003).

${ }^{6}$ Bilodeau and Slivinski (1997) propose that a pre-commitment by the monopoly charity to an allocation rule which honors donors' contributions to specific causes can solve this policy dilemma.

${ }^{7}$ Recent theoretical models of several fundraising techniques include publicizing donor names and contribution amounts (Glazer and Konrad, 1996; Harbough, 1998; Romano and Yildirim, 2001), raffles (Duncan, 2002), using seed money and refunds (Andreoni, 1998), and leadership giving (Andreoni, 2006b and Vesterlund, 2003).

${ }^{8}$ In this context, Rose-Ackerman (1982) uses the word 'ideology', Economides and Rose-Ackerman use (1993) 'type', and Andreoni and Payne (2003) use 'quality'. We follow Rose-Ackerman (1982).

${ }^{9}$ As we refer to it, a social optimum in a charity market is achieved when the total amount of charitable contributions received by all charities that operate within the market is maximized after the costs associated with fundraising are incurred.
} 
We argue that a policy maker can implement a regulatory mechanism in order to achieve the socially desirable amount of fundraising and the number of charities. Basically, this mechanism can be summarized in two steps. In the first step, policy maker regulates entry into the charity market. In the second step, given the initial cost of fundraising, he either imposes a tax that increases the cost of fundraising up to the optimal level and redistributes the tax revenue among the charities or subsidizes charities and decreases the cost of fundraising. However, this subsidy is financed initially from charities, possibly in the form of entry fees to the market. This mechanism guarantees that the optimal number of charities operate in the market and the overall net funds raised by all charities are maximized.

This paper is organized as follows. The next section presents the model and discusses the equilibrium properties. Section three introduces a utilitarian social welfare function and obtains the optimum number and ideological distribution of charities. Section four introduces the policy maker and presents a regulatory policy that always results in an efficient outcome. Section five discusses the main implications of the model and proposes some extensions. Section six concludes.

\section{The model}

Suppose that there are a finite number of charities in the market with different ideologies. As we refer to it, ideologies are qualitative differences among charities that operate within the same category of charitable activity. ${ }^{10}$ For instance, within a category of charities that offer fellowships for college education, one charity may give priority to students majoring in social sciences while another may offer financial assistance for those who are majoring in engineering. Following Economides and RoseAckerman (1993), we treat the ideology of a charity as a point on a circumference of length one. The objective of each charity is to maximize services that it provides to public. Since private contributions are the only source of finance, charities strategically target potential donors to solicit donations.

Let $I$ denote the ideology space and $Y=\left\{y_{i} \in I \mid i \in N\right\}$ be the ideology set of charities that operate within a representative charitable category where $N=\{1, \ldots, n\}$ is the set of charities. Hence, every charity $i$ has a unique ideology location along the circumference as plotted in Figure 1, panel A, which is denoted as $y_{i}{ }^{11}$ There are also donors in the society, whose ideologies are continuously and

\footnotetext{
${ }^{10}$ We refer to different categories in which individuals contribute to charitable causes. Although there are several charitable categories, the standard practice is to classify the charitable activity into broad categories. For example, recent data on charitable activity in the United States (PSID, 2005) obtain information on several broad categories such as giving to religious organizations, education, health, and environment.

${ }^{11}$ The ideology space can also be transformed into a unit interval as in Figure 1, panel B. This transformation proved
} 
uniformly distributed along the circle, through which they are ordered accordingly. ${ }^{12}$ For example, a donor, who may contribute to a charitable category, has also an ideology point, say $x \in I$. Hence, donors also differ in the charitable services to which they would like to contribute. Continuing with our previous example, while a donor may contribute more to a charity that offers fellowships to social science majors, another may give more to a charity that offers fellowships to engineering majors.

\subsection{Donors}

Every donor is endowed with a fixed amount of dollars $g>0$ to donate. ${ }^{13}$ Since each donor donates a fixed amount no matter what others do, the main motivation for giving is warm-glow. People contribute to charities because they are sympathetic to the causes supported by their favorite charity. ${ }^{14}$

Following Andreoni and Payne (2003), we assume that people do not give unless they are solicited by a charity. Charitable solicitations are imperfect signals that inform the potential donor that a particular charity exists and on the areas the charity focuses on. The signals are imperfect in a sense that they can only roughly inform the donor on how close her ideology is to that of the charity. Hence, there are errors associated with the donors' perceptions of the ideologies of the charities that solicited them. In particular, we assume that errors associated with signals are such that for any given donor $x$ and any given set of charities $Y(x) \subseteq Y$ that have solicited $x$, the donor believes that charity $i$ is ideologically closest to her with a probability $p_{i}$. We define $p_{i}$ as

$$
p_{i}\left(y_{i}, x ; Y(x)\right)\left\{\begin{array}{c}
1, \text { if } y_{i}=x \\
\frac{1 / \ell\left(x, y_{i}\right)}{\sum_{y_{j} \in Y(x)}\left[1 / \ell\left(x, y_{j}\right)\right]}, \text { if } y_{i} \in Y(x) \text { and } x \notin Y(x) \\
0, \text { if } y_{i} \notin Y(x) \text { or }\left\{y_{i}, x\right\} \subset Y(x) \text { and } y_{i} \neq x
\end{array}\right.
$$

where $\ell(x, y)$ is the minimum of the clockwise and counterclockwise distances along the unit circle from

to be useful for illustrative purposes. We provide a formal definition in Appendix B.

${ }^{12}$ Here, for expositional convenience, we assume that ideologies of individuals are uniformly distributed. However, the implications of the model can be altered accordingly under different distributions of ideologies.

${ }^{13}$ It is also possible to assume heteregenous donation levels across donors. However, such an assumption further complicates the model without altering its main implications.

${ }^{14}$ An example for pure warm-glow giving would be donations to emergency response organizations such Red Cross. In response to the recent earthquake disaster in Haiti, many people donated small amounts to Red Cross without taking into consideration of what other people would donate or how much the government would give to the earthquake victims. In this example, the cause that people are giving to is not a pure public good in a sense that not all people but only the recipients (earthquake victims) will benefit from it. Hence, the main motivation for giving to the earthquake victims was warm-glow. By generalizing this example, we believe that warm-glow is the dominant driver of donations to those campaigns that require enormous amount of funding and for which total donations are certain to be only a fraction of the ideal amount that has to be collected. 
point $x$ to $y$ for all $x, y \in I .{ }^{15}$ The charities' real ideological views are correctly revealed to donors only after donations have been made, and the charities make use of these donations to produce charitable services.

A representative donor's preferences are represented by:

$$
U(x)=\left\{\begin{array}{c}
\frac{1}{2}-\min \ell(x, y) \text { if donation made to some charity } y \\
0 \text { otherwise }
\end{array}\right.
$$

An implication of the donor's preferences is that she receives a higher satisfaction from making a donation to the charity that is ideologically closest to her. However, since she does not know which charity is ideologically closest to her at the time of the solicitation, she makes a donation of $g$ dollars to the charity that she believes to be the closest to her to maximize her expected utility. Given this assumption, charity $i$ 's expected return from soliciting a donor is simply $g p_{i}\left(y_{i}, x ; Y(x)\right)$.

Notice that $p_{i}$ is decreasing among solicitors according to their ideological distance from donor $x$ and that whenever a charity's and donor's ideologies are identical, the donor makes a donation to that particular charity with certainty. Another implication of equation $(2)$ is that $U(x) \geq 0$ when $|Y(x)| \geq 1$. Hence, a solicitation yields positive utility for a donor.

\subsection{Charities}

In our model, charities produce services and provide them to the public. Production of services is funded through charitable contributions. Assume that there exists a continuum of charities with different ideologies that want to operate in a given charitable category. The fundraising decision and the resulting payoffs of charities can be summarized as a two stage game. In the first stage, charities simultaneously decide whether to enter the market or not. If a charity does not enter the market, then it receives a zero payoff and does not proceed to the second stage. However, if a charity enters the market, then it incurs a fixed cost, proceeds to the second stage and plays the solicitation game. At the end of the second stage, it uses contributions to produce charitable services.

\subsubsection{The solicitation game}

In the second stage, given the ideology distribution of other charities in the market, each charity simultaneously decides to solicit donations or not. Assume that a finite set of charities $N$ have

\footnotetext{
${ }^{15}$ In equation (1), we assume that $|Y(x)|>1$, otherwise $p_{i}=1$, whenever a single charity solicits the donor. The rule presented here is a special case of the general rule. We discuss the signal generating process and general rule in Appendix A.
} 
entered the market in the first stage. ${ }^{16}$ The solicitation game can be described by the following list: $G=\left(N,\left(\sigma_{i}, \phi_{i}\right)_{i \in N}\right)$ where $\phi_{i}$ is the associated payoff as described below and $\sigma_{i}=\left\{f_{i} \mid f_{i}: I \rightarrow\right.$ $\{s, d\}\} .{ }^{17}$ Here, $f_{i}(x)=s$ denotes that donor $x$ has been solicited by charity $i$, whereas $f_{i}(x)=d$ denotes the opposite.

In analyzing the equilibrium of this game, we adopt a pure strategy SPNE as our equilibrium concept. Notice that in any SPNE, $\phi_{i} \geq 0$ is satisfied for all charities that have entered the market. Otherwise, there exists a charity $j$ such that $\phi_{j}<0$. This implies that charity $j$ did not play its best response in the first stage which contradicts the assumption that we have a SPNE.

\subsubsection{The payoffs}

We assume that fundraising is costly and that each charity has to pay a fixed marginal cost of $c \in(0, g)$ for each individual that it has solicited. Then, the marginal expected net donation received by charity $i$ from donor $x$ is given by

$$
\pi_{i}\left(y_{i}, x ; Y(x)\right)=\left\{\begin{array}{c}
g p_{i}\left(y_{i}, x ; Y(x)\right)-c \text { if } y_{i} \in Y(x) \\
0 \text { otherwise }
\end{array} .\right.
$$

Suppose also that there is a fixed $\operatorname{cost} F \in(0, g-c)$ that is associated with establishing a charity and starting a fundraising campaign. Examples of such a cost may include the Internal Revenue Service (IRS) costs that have to be paid by all charities to gain a tax exempt status and the standard cost of capital. Therefore, at the end of the second stage, net funds available to charity $i$ to provide services are given as

$$
\phi_{i}=\int_{I} \pi_{i}\left(y_{i}, x ; Y(x)\right) d x-F=\Pi_{i}-F
$$

\subsubsection{Production of charitable services}

The only input to charities for the production of their services is the net funds $\phi_{i}$. We further assume that charities posses a constant returns to scale (CRS) production technology. Hence charity $i$ 's production is given by $\phi_{i}$ for all $i \in N$. An implication of this production technology is that total production is a function only of total net funds, which is only a function of total net donations

\footnotetext{
${ }^{16}$ The existence of fixed costs guarantees that a finite number of charities enter the game in a Sub-game Perfect Nash Equilibrium (SPNE).

${ }^{17}$ A strategy of a charity is a function that maps every point on the circle to the set $\{s, d\}$. Notice that this is the pure strategy of the charity. For simplicity, we restrict our attention to these strategies only.
} 
$\sum_{i \in N} \Pi_{i}\left(y_{i}, x, Y(x)\right)$ given the number of charities. Therefore total production is defined as:

$$
\Theta=\sum_{i \in N} \phi_{i}=\sum_{i \in N} \Pi_{i}-n F
$$

We assume that each charity maximizes its production of services. ${ }^{18}$ A sufficient but not necessary condition to maximize production is to maximize marginal net donations from every individual. By altering its strategy for a single individual, a charity can neither decrease nor increase its payoff. Hence, if we allow each charity to choose its strategy without maximizing marginal net donations at an individual level at every point on the ideology space, a charity would have infinitely many strategies that would result in the same payoff. In order to address this problem, we impose a restriction on the equilibrium strategy profiles. First, we describe a set of games played at each point on the unit circle. Let $f_{i}(x)=\{s, d\}$ be the strategy set of charity $i$ where $s$ is the strategy of the charity to solicit donor $x$ and $d$ not to. Hence, the solicitation game consists of an infinite number of games played at each point on the ideology space $I$, and given $x$, each game is denoted by $G^{x}$. Formally, we describe a game at each point by the following list: $G^{x}=\left\{N,\left(f_{i}(x), \pi_{i}\left(y_{i}, x ; Y(x)\right)_{i \in N}\right\}\right.$, where $\pi_{i}\left(y_{i}, x, Y(x)\right): \prod_{j \in N} f_{j}(x) \rightarrow[-c, g-c]$. Using this notation, we formalize the following requirement for the equilibrium strategies.

Requirement 1 (R1) $\beta^{*}$ satisfies $R 1$ if $\beta^{*} \in\left\{\alpha^{*} \mid \alpha^{*}=\left\{f_{1}^{*}, f_{2}^{*} \ldots, f_{n}^{*}\right\}\right.$ and $\alpha^{*}(x)=\left\{f_{1}^{*}(x), . ., f_{n}^{*}(x)\right\}$, is an equilibrium of the game $G^{x}$ for all $\left.x\right\} .^{19}$

Notice that $R 1$ relies on having pure strategy equilibria for all $G^{x}$ such that $x \in I$. The following proposition shows that such equilibria actually exist and hence, there always exists a strategy profile $\beta^{*}$ that satisfies $R 1$.

Proposition 1 Regardless of the level of c, there always exists a pure strategy Nash equilibrium (NE) of the game $G^{x}$ for all $x \in I$.

For the rest of the paper, we assume that charities maximize marginal net donations from every single donor and that every equilibrium satisfies $R 1$. This assumption simplifies the interactions among charities and makes the model easily tractable without affecting its main implications.

\footnotetext{
${ }^{18}$ We assume charities are net revenue maximizers. There is conflicting evidence however on whether this assumption holds. For example, Khanna, Posnett, and Sandler (1995) find that the charities in the health and overseas sectors maximize net revenue, whereas charities in the social welfare sector do not.

${ }^{19}$ Note that it trivially follows that $\beta^{*}$ is an equilibrium strategy profile, whenever it satisfies R1.
} 


\subsection{Equilibrium properties}

A socially desirable outcome of the solicitation game should maximize total services that are provided to public. In order to maximize total charitable services, a necessary condition is to maximize total net donations received by all charities. When some donors are solicited by multiple charities, this result may not be obtained due to intense competition for donations. This leads to excessive fundraising costs. However, if almost every donor is solicited exactly once, then excessive fundraising costs are eliminated and exactly $c$ dollars have to be spent in order to collect $g$ dollars from a single donor.

Since donors' utilities increase when they are solicited and donate, another important question is whether every donor has been solicited in the solicitation game. The following proposition summarizes the result associated with this question.

Proposition 2 Regardless of the level of solicitation costs, every donor is solicited in the NE of the solicitation game.

Next, we investigate the equilibrium properties and discuss the conditions that guarantee the maximization of total net donations. The following proposition summarizes our results.

Proposition 3 Assume $|Y(x)|>1$. (i) The NE of the solicitation game maximizes total net donations iff $c \geq g / 2$. (ii) There are excessive fundraising costs, if $c<g / 2$.

The next section provides a simple example in order to explain the dynamics of the solicitation game.

\subsection{Example with two charities}

Suppose that there are only two charities in the market with ideology locations $y_{1}$ and $y_{2}$ as in Figure 1, panel A. Assume that these two charities solicit donations from a donor whose ideology is located at point $x$. We plot the returns from soliciting donor $x$ in Figure 2, given that the donor is solicited by both charities. Notice that in constructing Figure 2, we use the transformed ideology space in Figure 1, panel B. It is clear that if the ideology of the donor and the charity is the same, then the donor contributes to that particular charity with certainty. For instance, the donor located at point 0 in Figure 2 gives to the first charity with certainty. Similarly, the donor located at $T\left(y_{2}\right)$ donates to the second charity, which implies $p_{2}=1$.

In Figure 2, we analyze the solicitation game for two particular cases. First, assume that the cost of fundraising is lower than $g / 2$ such that $c=c_{l}$. In equilibrium, donors whose ideology points are 
located in $\left[0, a_{1}\right)$ or $\left(a_{4}, 1\right)$ intervals are only solicited by the first charity since in these intervals, the cost of solicitation is higher than the expected return for the second charity. Similarly, donors whose ideology points are located in interval $\left(a_{2}, a_{3}\right)$ are solicited only by the second charity. Donors whose ideologies are located in either $\left(a_{1}, a_{2}\right)$ or $\left(a_{3}, a_{4}\right)$ intervals are solicited by both charities which causes excessive fundraising in the market. Therefore, as long as $c<g / 2$, there exists excessive fundraising costs.

Next, assume that the cost of fundraising is relatively high such that $c=c_{h}$. In the equilibrium, similar to the above analysis, donors whose ideology points are located in $\left[0, a_{1}\right)$ or $\left(a_{4}, 1\right)$ intervals are solicited by the first charity and donors whose ideologies are in $\left(a_{2}, a_{3}\right)$ are solicited by the second charity. If both charities solicit donations from $\left(a_{1}, a_{2}\right)$ or $\left(a_{3}, a_{4}\right)$ intervals, then the cost of fundraising exceeds the expected contribution amount for both charities. Therefore, for these intervals, any allocation of donors among the two charities is possible as long as each donor is solicited by only one charity. Hence, if $c \geq g / 2$, the NE of the solicitation game maximizes total net donations.

It follows from proposition 3 that whenever $c \geq g / 2$, total net donations are maximized. This result is also illustrated by this example. However, the number of charities that enter the market in the first stage has an adverse effect on the aggregate production of charities. Furthermore, the number and location of charities also affect donors' utilities. In the next section, we derive a utilitarian social welfare function and investigate whether unregulated charitable markets produce socially desirable outcomes.

\section{Social Welfare}

We have shown that depending on the cost structure, total net donations may not be maximized without market intervention. This result together with the production structure, implies that total services provided may not be maximized. In this section, we introduce a utilitarian social welfare function and show that a similar result holds regarding the maximization of social welfare. That is, given the cost structure, the equilibrium reached by the solicitation game may be sub-optimal.

As mentioned before, there are two types of agents, namely donors and charities. We assume that charities do not posses utility functions, but rather they affect the social welfare through their net production, which is distributed in someway back to society. ${ }^{20}$ Hence, we define the social welfare function as the sum of donors' utilities and total productions by charities. Formally, the utilitarian

\footnotetext{
${ }^{20}$ Since we assume that society consists of individuals with linear utility functions, how total net production is distributed is irrelevant.
} 
social welfare function can be expressed as: ${ }^{21}$

$$
W=\int_{I} U(x) d x+\Theta
$$

We assume that the production function of charities is linear. Hence, social welfare as defined in equation (6) is a function of the number, location, and action of charities.

\subsection{Social planner's problem}

Given any number and ideological distribution of charities, a social planner may organize the market in a way such that every donor is solicited exactly once by that charity which is ideologically closest to her. ${ }^{22}$ In this case, donors' utilities and total production of charitable services are maximized. Subject to such regulation social welfare can be expressed as

$$
W=\int_{I}\left(\frac{1}{2}-\min _{i \in N}\left\{\ell\left(x, y_{i}\right)\right\}\right) d x+(g-c)-n F .
$$

The social planner's problem in equation (7) now becomes that of choosing the number and ideological locations of charities. However, in this maximization problem, the choice set for ideological locations can only be defined after the number of charities is chosen. In order to simplify this problem, we define a value function $V$ for social welfare that yields the highest attainable level of social welfare as a function of $n$ :

$$
V(n)=\max _{y_{1}, \ldots, y_{n}} \int_{I}\left(\frac{1}{2}-\min _{i \in N}\left\{\ell\left(x, y_{i}\right)\right\}\right) d x+(g-c)-n F
$$

Notice that the second term of the value function depends on the ideological locations of charities. Hence, we must first find the ideology locations that maximize this term. Given the number of charities, the following lemma provides the optimal ideology choice of charities.

Lemma 1 Given any number of charities $n>1, \int_{I}\left(\frac{1}{2}-\min _{i \in N}\left\{\ell\left(y_{i}, x\right)\right\}\right) d x$ is maximized when the ideological distance between any two consecutive charities is the same, which yields $V(n)=\left(\frac{1}{2}-\frac{1}{4 n}\right)$.

Hence, we can rewrite equation (8) as

$$
V(n)=\left(\frac{1}{2}-\frac{1}{4 n}\right)+(g-c)-n F
$$

\footnotetext{
${ }^{21}$ This definition implicitly assumes a positive number of charities. Otherwise, social welfare equals to zero.

${ }^{22}$ This claim is verified in the next section. To guarantee this result, a social planner may regulate the market through subsidies or taxes, such that the per unit cost of solicitating a donor is $g / 2$ for a charity. See also Lemma 2 (ii) in Appendix C.
} 
Maximizing this function with respect to $n$, such that $n \in Z^{+}$, yields the optimal number of charities. The set of the welfare maximizing number of charities $n^{*}$ is given by

$$
n^{*}=\left\{\begin{array}{l}
\{1\} \text { if } \frac{1}{2 \sqrt{F}} \leq 1 \\
n^{m} \text { if } \frac{1}{2 \sqrt{F}}>1
\end{array}\right.
$$

where $n^{m}$ is basically $\frac{1}{2 \sqrt{F}}$ rounded up or down to an integer, or both, depending on which of these two integers yields a higher social welfare level when inserted into $V(n)$. We summarize our results in the following proposition.

Proposition 4 (i) In order to maximize social welfare, every donor has to be solicited exactly once by $n^{*}$ charities that are exactly $\frac{1}{n^{*}}$ apart from the adjacent charity in the ideology space. (ii) If the marginal cost of diversity $F$ is sufficiently low than the optimal structure of the market is not a monopoly.

If the optimal market structure that maximizes social welfare is a monopoly, then the relevant policy is straight forward and social optimum can be achieved through market regulation and imposing barriers to entry. Here, we focus on a more interesting case in which the optimal market structure is not a monopoly and for the remainder of our analysis, we assume that $F$ is such that $n^{*} \geq 2$.

\subsection{Inefficiencies in unregulated charity markets}

The following proposition presents our results regarding market efficiency.

Proposition 5 (i) If $c<g / 2$, then all SPNE are inefficient. (ii) If $c>g / 2$, then only a subset of SPNE are efficient.

This proposition implies that in an unregulated charity market, when costs of solicitation are unfavorably low, all equilibria necessarily lead to inefficient results. Moreover, even if there are no problems associated with the cost structures, only a very small subset of SPNE leads to efficient results.

\section{Policy maker}

We have shown that in a competitive market, total net donations raised by charities are maximized if $c \geq g / 2$. We now investigate whether a policy maker can achieve an equilibrium that maximizes total 
net donations while inducing the optimal number and ideology locations of charities in the market. In our model, a natural policy to maximize the total net donations is to regulate the market structure. In the extreme case, suppose that entry is heavily regulated such that only one monopoly united charity is allowed to operate in the market. Furthermore, assume that charities that want to operate in the market are not permitted to solicit donors independently and hence must join the united charity. Obviously, the monopoly united charity economizes on fundraising costs and maximizes total net donations since regardless of the cost of fundraising, each donor is solicited only once. Although this policy seems to be effective, it may also be far from ideal since it eliminates the ideological diversity in the charity market. ${ }^{23}$ In reality, not only the volume of services but also the variety of services is important since people enjoy the existence of charities which are ideologically close to them. Therefore, the trade-off between diversity and volume of services provided is an important policy dilemma.

A possible solution to this dilemma is to organize the monopoly united charity in such a way that donors' contributions to specific purposes is honored. Bilodeau and Slivinski (1997) show that this can be achieved by a pre-commitment device. Such a device is generally not used however, and the existence of only one charity is hardly ever justifiable. ${ }^{24}$ We argue that a carefully designed mechanism implemented by a policy maker can maximize total net donations without sacrificing the variety of services. As we define him, a policy maker has limited regulatory power and financial resources to enforce his policies. In particular, he uses tax and subsidy to regulate the market. He neither has financial resources besides those generated from charities nor a right to keep the revenues raised by taxing charities. Hence, whenever he wishes to impose a subsidy, he has to finance it from charities, and whenever he wishes to tax charities, he has to redistribute the revenues back to charities. Furthermore, he collects a fixed entry or registration fee from each charitable organization that would like to operate in the market. Therefore, he has a right to award operating licences or impede unlicensed charities from operating. ${ }^{25}$

In reality, there are several regulatory bodies that can impose restrictions on charities. The power of the policy maker and the nature of regulations widely differ in each state. For example, some states require a maximum fundraising expenditure based on the donations received, while some others do

\footnotetext{
${ }^{23}$ Fisher (1977) also discusses that donors may be worse off with a united monopoly charity because they are being forced to make a tied purchase.

${ }^{24}$ Bilodeau and Slivinski (1997) argue that individual chapters of national organizations are an exception.

${ }^{25}$ In reality, policy makers may have outside financial resources. However, the mechanism that we propose can easily be modified to incorporate this possibility.
} 
not. However, the above assumptions are generally in line with the current practices in the U.S. For example, the most common requirement in the U.S. is to impose a registration fee on new charities that would like to operate in the market. Currently, forty five states require registration fees to award operating licenses. As a natural consequence of this regulation, the policy maker has a right to prevent unregistered or unlicensed charities from operating in the market.

In a regulated market, a charity has to pay a registration fee in order to operate in the market but its fixed cost is paid by the policy maker. Let $E_{i}$ denote the entry fee for charity $i$. Equation (4) transforms to

$$
\widetilde{\phi}_{i}=\Pi_{i}-E_{i}
$$

As we mentioned before, $E_{i}$ is the policy maker's only source to pay all fixed costs of entrants and to finance subsidies. No outside financial sources imply that

$$
\sum_{i \in N} E_{i}=n F+\left(c-c_{o}\right) \Gamma
$$

where $c_{o}$ denotes the subsidized or taxed cost of solicitation and $\Gamma$ is the measure of solicitations that have been made.

Given equation (12), our purpose is to develop a mechanism that maximizes total net donations and allows the optimal number of charities with the optimal ideological distribution to operate in the market. We proceed by illustrating a negative result, which will motivate our next assumption.

Proposition 6 There does not exist a mechanism that can be designed by the policy maker that would induce $n>\bar{n}$ charities to operate in the market, where $\bar{n}=(g-c) / F$.

As mentioned before, the policy maker has limited financial power to enforce his policies. Therefore, we rule out cases for which the optimal number of charities is so high that without any outside funding, it is impossible to support an equilibrium in which the optimal number of charities coexist. Proposition 6 introduces a critical number above which it is no longer possible to support equilibria without additional funding.

Formally, we assume that $F$ is such that $\bar{n}>n$ for all $n \in n^{*}(F)$. This is a simplifying assumption which allows us to ignore feasibility constraints. Alternatively, it can be thought of as a condition defining the charitable activities that we focus on. We are only interested in charitable activities that do not require any outside funding. Notice also that together with our previous assumption, we have the following constraint on the optimal number of charities: $\bar{n}>n>1$ for all $n \in n^{*}$. 
An obvious implication of proposition 6 is that a SPNE, in which there exists a number of charities for which the total fixed costs exceed the maximum possible net donations, cannot be reached by a mechanism designed by a policy maker without any outside funding. This observation also implies that if the optimal number of charities is too high, it is necessary to finance the charity market via sources other than those come from the charities themselves. In the next sub-section, we continue by proposing a mechanism that yields a SPNE.

\subsection{The mechanism $(\Delta)$}

In order to maximize total net donations, the policy maker can implement the following mechanism in which $n^{*}<\bar{n}$ charities coexist.

Stage 1: The policy maker randomly draws an ideology point $y_{1}$ from the ideology space.

Stage 2: It selects $n^{*}$ charities on the ideology space ( $y_{1}$ being one of them) such that each charity is $1 / n^{*}$ apart from the next charity on the ideology space.

Stage 3: These charities are offered two options:

(i) Pay $E=F+\frac{(c-g / 2)}{n^{m}}$ up-front to the policy maker and solicit donors at the cost of $g / 2$, or do not enter the charity market, if $c>g / 2$ (subsidy).

(ii) Pay $F$ up-front to the policy maker and and solicit donors at the cost of $g / 2$, or do not enter the charity market, if $c<g / 2(\operatorname{tax})$.

Stage 4: The policy maker collects the E's (or F's if $c<c_{0}$ ) from the charities that enter the market and pays the fixed costs for all charities.

Stage 5: Charities begin operating and soliciting donors. Whenever a donor is solicited, the charity pays $g / 2$ and the policy maker either pays the rest of the cost if $c>g / 2$ or collects the difference $g / 2-c$ if $c<g / 2$.

Stage 6: If $c<g / 2(\operatorname{tax})$, the policy maker pays each charity an additional $\frac{(g / 2-c)}{n^{m}}$. Otherwise, this stage does not exist.

Stage 7: Charities produce services with the monetary sources they have.

Proposition 7 Every SPNE obtained by $\Delta$ is efficient and satisfies the no-outside funding constraint.

The powerful result of this mechanism is that not only it induces the optimal outcome, but also the equilibria induced by this mechanism are always optimal. In other words, it alleviates market inefficiencies that are due to cost structures and coordination problems. Although this mechanism 
requires $\bar{n}>n^{*}$, this is only a feasibility requirement. With outside funding opportunities, a similar mechanism can also be designed.

\section{Discussion of results}

Throughout the paper, we assumed that donors are endowed with a fixed amount, $g$, to donate. This assumption is inconsistent with the expectation that a donor's marginal utility from donation would be decreasing in the total amount collected by charities. Accordingly, the more donors expect charities to collect, the less would they be willing to give to them. This aspect of charitable contributions is widely discussed in the literature and would be important in determining the effects of government contributions to charities, tax reductions offered to charities, and other administrative issues related to the way charitable contributions are collected. However, this inconsistency is unlikely to alter our main results and their implications. This conjecture is likely to follow from the fact that the conclusions reached in this paper are related to distributive aspects in charity markets rather than the magnitude of aggregate donations.

In our model, optimality requires that a number of equidistant charities solicit only those donors to whom they are the closest charity. This result is likely to follow in a model incorporating crowdingout, because crowding-out relates only to the amount of charitable contributions made by each donor. A donor's contribution will not be affected by the number of solicitations received by him, as long as this number does not affect his expectation concerning the amount of donations that will be collected by his favorite charity. Accordingly, it will be still optimal for each donor to be solicited by a single charity. This will be achieved by having equidistant charities that solicit only those donors to whom they are the closest charity. Hence, crowding-out is not likely to affect our first main result.

The next main insight provided in this paper is that the optimal number of charities does not need to be one. This follows from our assumption that donors care about the ideology of the charity that they give to. A variant of this assumption which incorporates crowding-out would be that donors care about charities' ideologies and the amount of total donations they expect them to collect. Furthermore, a reasonable version of this assumption would have the following characteristic: A donor would be a happier person in a world where two charities (one of which is ideologically closer to him) each collect $\$ 1$ million than in a world where a single charity that is ideologically far away from him

collects $\$ 2$ million. Given this reasonable alternative assumption, our result concerning the potential non-desirability of a monopoly is likely to hold. 
To verify our conjecture, consider a world where there is a single charity. Allowing a second charity (that is 0.5 away from the initial charity) to enter the market and regulating it such that both charities solicit only those donors to whom they are the closest charity will increase the total amount of charitable contributions received. This follows because each donor who is closer to the ex-monopoly will increase her contribution, knowing that the monopoly's total collection will drop when a second charity enters the market. Given the fact that the ex-monopoly will collect donations from half of the donors, donations collected by it will exceed half of what it used to collect as a monopoly. Since the entrant charity will be in a symmetric situation, its collected donations will also exceed half of what was collected in a monopoly structure. Hence, total charitable contributions will increase, which will presumably lead to an increase in welfare (through $\Theta$ ). Donors who are closer to the entrant charity will also be happier because they make contributions to the charity that is ideologically closer to them. The only people who may be less happy are the ones who are closer to the ex-monopoly charity because donations collected by this charity are presumably less than what they once were. But this drop in the ex-monopoly's donors' utilities will be off-set by the increase in the entrant's donors' utilities, because a drop in the ex-monopoly's revenue also implies an increase in the marginal utility obtained by its donors (an implication of crowding-out). Hence, moving to a duopoly increases welfare through $\Theta$ and donors' aggregate utilities, while lowering it through an increase in fixed costs $(F)$. Therefore, our main proposition that a monopoly is undesirable if $F$ is sufficiently low remains valid, even under a reasonable crowding-out assumption.

Since crowding-out is not directly incorporated in the model, it seems at first sight that our model is similar to traditional models of product differentiation. However, due to the absence of explicit pricing in charity markets, the model presented in this paper is not similar to comparable models for differentiated goods. In this paper, we considered a two stage game played by charities. In the first period, charities decide whether to enter the charitable market. In the second stage, those who have entered solicit donations from donors. The analog of this game for differentiated goods would have three stages, or two stages with a second stage where firms' strategies comprise of choosing the consumers to send advertisements and choosing prices for their goods. As such, the analysis of such a game would be more sophisticated, and depending on the modelling choice it may not have a solution. ${ }^{26}$

Furthermore, compared with the traditional models of product differentiation, our analysis is

\footnotetext{
${ }^{26}$ See, for instance, d'Aspremont, Gabszewicz, and Thisse (1979) showing in the standard Hotelling (1929) framework that "no equilibrium price solution will exist when both sellers are not far enough from each other". Similar problems are likely to be encountered with the inclusion of price in our model.
} 
conducted at a higher level of generality. Appendix A lists four simple and intuitive properties that donors' behavior must satisfy for our analysis to remain valid. To incorporate pricing by firms in combination with consumers' tastes for product varieties, the level of generality in our model must be reduced. This follows from the fact that a consumer's likelihood of buying an advertised good will depend not only on how close the product is to that consumer's taste, but also on its price. Accordingly, a trade-off between price and taste must be specified for the consumer. This will necessarily require an alteration of the generalized properties listed in Appendix A, which will lead to a reduction in generality. This is another reason as to why our model is more appropriate for analyzing charitable giving rather than interactions between consumers and firms in a market for advertised and differentiated goods.

\section{Conclusion}

In this paper, we develop a simple spatial model of fundraising, in which charities select a target population to solicit donations. Using a utilitarian social welfare function, we first show that everything else equal, diversity is a desirable aspect in charity markets. However, there are fixed costs associated with establishing charities, which can be viewed as the marginal cost of diversity. Hence, there is a trade-off associated with the total production of charities and diversity.

Next, we show that in a competitive charity market with no entry barriers and outside intervention, the number of charities in the market and/or the overall net funds raised by charities may be suboptimal. We analyze whether a social planner with limited regulatory powers can overcome these inefficiencies and show that a mechanism which regulates the entry in the market and imposes either a tax or subsidy on fundraising costs can be designed to achieve optimal outcomes. Therefore, direct market structure regulation seems to be an effective way of solving the trade-off between the variety and volume of charitable services. Furthermore, such a policy may be employed even if policy maker has very limited financial resources and few regulatory tools.

In contrast to the conventional wisdom that a monopoly charity is socially desirable, our model does not necessarily imply monopoly as the optimal market structure. We show that if fixed costs associated with establishing charities are sufficiently low, then the optimal market structure is not a monopoly. Besides its policy implications, this result is particularly important primarily for two reasons. First, joining a united monopoly charity is generally undesirable for ideologically disparate charities. Second, monopoly charities are rarely observed and the diversity of ideologies is almost 
always honored in existing charity markets.

We do not, however, advocate the adoption of our regulatory mechanism as it is presented in section 4 . The proposed mechanism seeks to identify a method to achieve efficiency absent any constraint (e.g. political, technological or constitutional). In reality, however, there are many constraints. A technological constraint would be the determination of any charity's true ideological location. A constitutional one would be the Bill of Rights. While determining policies, legislators must take these constraints into consideration. The use of our mechanism, then, is to allow legislators to come up with policies which approximate the solution proposed by our mechanism while taking realistic considerations into account. Such policies may include the use of subsidies to encourage charities with under-performing ideologies (as is done in many affirmative action programs) in combination with an increase in the fixed costs of establishing charities. Such a policy would likely have effects similar to the proposed mechanism without violating the Bill of Rights.

\section{A Generalized signaling process}

Suppose that charity $i$ with the ideological position $y_{i}$ produces a signal $s_{i}$. If the donor and the charity share the same location, this signal produces perfect information, i.e. the donor is certain that charity $i$ and she share the same ideological location. Otherwise, let $h_{i}\left(s_{i}\right)$ be the density function which defines the donor's likelihood of receiving $s_{i}$ from charity $i$. We assume that $h_{i}$ satisfies the following properties:

(i) $h_{i}(a)=h\left(\ell\left(a, y_{i}\right)\right) \geq h_{i}(b)=h\left(\ell\left(b, y_{i}\right)\right)$ iff $\ell\left(a, y_{i}\right) \leq \ell\left(b, y_{i}\right)$ for all $i$.

(ii) $h_{i}(x)>0$ for all $x \in I$.

(iii) $\int_{x \in I} h_{i}(x) d x=1$.

Our model assumes that donors believe that charity $i$ is ideologically closest to them with a probability $p_{i}$ which satisfies a unique rule given in equation (1). This rule is used for expositional convenience and is not necessary to derive any of the results which follow. The signal generating process outlined above leads donors to donate to the charity from which they receive the closest signal. This in turn leads a charity to have a probability $p_{i}$ of receiving donations from donor $x$, which follows the general properties outlined below. These properties are the only necessary properties to achieve the results presented in this paper and defined as follows:

If $|Y(x)|=1$, then $p_{i}\left(y_{i}, x ; Y(x)\right)=1$, for $y_{i} \in Y(x)$. If $|Y(x)|>1$, the donor makes a donation of $g$ to charity $i$ with $y_{i} \in Y(x)$ with a probability $p_{i}$ according to a rule that satisfies the following 
properties:

(i) $\forall i$ with $y_{i} \in Y(x), p_{i}\left(y_{i}, x ; Y(x)\right) \geq 0$ and $\sum_{i} p_{i}\left(y_{i}, x ; Y(x)\right)=1$.

(ii) $p_{i}\left(y_{i}, x ; Y(x)\right)=1 \Longleftrightarrow \ell\left(x, y_{i}\right)=0$.

(iii) Let $Y(x)=\left\{y_{1}, y_{2}, \ldots, y_{i}, \ldots, y_{n}\right\}$ and $Y(x) \cap y_{a}=\emptyset=Y(x) \cap y_{b}$. If $y_{i} \neq x$, then $p_{a}\left(y_{a}, x,\{Y \cup\right.$ $\left.\left.y_{a}\right\}\right) \geq p_{b}\left(y_{b}, x,\left\{Y \cup y_{b}\right\}\right) \Longleftrightarrow \ell\left(x, y_{a}\right) \leq \ell\left(x, y_{b}\right)$.

(iv) If $\exists \mu \in Y(x)$ such that $\mu=x$, then $\forall i, j$ with $y_{i}, y_{j} \in Y(x) /\{\mu\}, p_{i}\left(y_{i}, x ; Y(x)\right)=p_{j}\left(y_{j}, x ; Y(x)\right)=$ 0. Otherwise, $\forall i, j$ with $y_{i}, y_{j} \in Y(x), p_{i}\left(y_{i}, x ; Y(x)\right) \geq p_{j}\left(y_{j}, x ; Y(x)\right) \Longleftrightarrow \ell\left(x, y_{i}\right) \leq \ell\left(x, y_{j}\right)$.

The proofs in Appendix C rely only on these properties.

\section{B Definitions}

This appendix presents formal definitions for some of the concepts that are discussed in the text. We also provide some additional definitions that will be useful in proving some of the propositions and lemmas.

Definition 1 Reference point $r$.

Let $d(x, y)$ be the clockwise distance from $x$ to $y$. Hence, $d(x, y) \leq \frac{1}{2} \Longleftrightarrow d(x, y)=\ell(x, y)$.

(i) For $|N| \geq 2$ and when there does not exist $i, j \in N$ such that $\ell\left(y_{i}, y_{j}\right)=\frac{1}{2}$, pick any two consecutive charities $y_{a}, y_{b}$ on the ideology space. Than pick $r \in I$ to be that point that satisfies $\ell\left(y_{a}, r\right)=\ell\left(y_{b}, r\right)=\frac{\ell\left(y_{a}, y_{b}\right)}{2}$.

(ii) If there exists $i, j \in N$ such that $\ell\left(y_{i}, y_{j}\right)=\frac{1}{2}$, due to the uniqueness of ideology points, it must be true that $|N|=2$. In this case pick one of the charities and call it $y_{1}$. Implicitly define $r \in I$ as that point that satisfies $d\left(y_{1}, r\right)=\frac{1}{4}$.

\section{Definition 2 Indices of charities.}

(i) For $|N| \geq 2$ and when there does not exist $i, j \in N$ such that $\ell\left(y_{i}, y_{j}\right)=\frac{1}{2}$, given the reference point $r$, index charities (including $y_{a}$ and $y_{b}$ ) according to their clockwise distance from $r$ such that $d\left(r, y_{i+1}\right)>d\left(r, y_{i}\right)$ for all $i \in N /\{n\}$. Since ideology locations of charities are unique, this ordering is well defined. Note also that, according to the new indexing, $\left\{y_{a}, y_{b}\right\}=\left\{y_{1}, y_{n}\right\}$.

(ii) If there exists $i, j \in N$ such that $\ell\left(y_{i}, y_{j}\right)=\frac{1}{2}$, due to the uniqueness of ideology points, it must be true that $|N|=2$. In this case, pick an arbitrary charity and call it 1 and call the other 2 .

Definition 3 Equal distance points $\left\{\gamma_{1}, \ldots, \gamma_{n}\right\}$. 
(i) For $|N| \geq 2$ and when there doesn't exist $i, j \in N$ such that $\ell\left(y_{i}, y_{j}\right)=\frac{1}{2}$, implicitly define $\gamma_{i} \in I$ to be that point which satisfies $\ell\left(y_{i}, \gamma_{i}\right)=\ell\left(y_{i+1}, \gamma_{i}\right)=\frac{\ell\left(y_{i}, y_{i+1}\right)}{2}$ for all $i \in N /\{n\}$, and $\gamma_{n}=r$. Note that $\ell\left(y_{1}, \gamma_{n}\right)=\ell\left(y_{n}, \gamma_{n}\right)=\frac{\ell\left(y_{1}, y_{n}\right)}{2}$.

(ii) If There exists $i, j \in N$ such that $\ell\left(y_{i}, y_{j}\right)=\frac{1}{2}$, due to the uniqueness of ideology points, it must be true that $|N|=2$. In this case let $\gamma_{1}=r$ and implicitly define $\gamma_{2}$ as that point that satisfies $d\left(y_{2}, \gamma_{2}\right)=\frac{1}{4}$.

\section{Definition 4 Transformed ideology space.}

Given $r$ define $T():. I \rightarrow[0,1)$ as $T(y)=d(r, y) . T(y)$ is the transformed ideology location of $y$ given the reference point $r$, which lies on the unit interval. This transformation implies the following:

For all $i \in N /\{n\}$ and for all $x$ such that $T(x) \in\left[T\left(y_{i}\right), T\left(\gamma_{i}\right)\right]$, it must be true that $\ell\left(x, y_{i}\right)=$ $T(x)-T\left(y_{i}\right)$. For all $i \in N /\{n\}$ and for all $x$ such that $T(x) \in\left[T\left(\gamma_{i}\right), T\left(y_{i+1}\right)\right]$, it must be true that $\ell\left(x, y_{i+1}\right)=T\left(y_{i+1}\right)-T(x)$. For all $x$ such that $T(x) \in\left[T\left(y_{n}\right), 1\right)$, it must be true that $\ell\left(x, y_{n}\right)=$ $T(x)-T\left(y_{n}\right)$. For all $x$ such that $T(x) \in\left[0, T\left(y_{1}\right)\right]$, it must be true that $\ell(x, 0)=T\left(y_{1}\right)-T(x)$.

\section{Proofs}

Proof of Lemma 1 By using the transformation $T($.$) , we have$

$$
\begin{aligned}
& \int_{I}\left(\frac{1}{2}-\min _{i \in N}\left\{\ell\left(y_{i}, x\right)\right\}\right) d x=\left[\frac{1}{2}-\int_{0}^{T\left(y_{1}\right)}(T(x)-0) d T(x)+2 \sum_{i=1}^{n-1} \int_{T\left(y_{i}\right)}^{\frac{T\left(y_{i}\right)+T\left(y_{i+1}\right)}{2}}\left(T(x)-T\left(y_{i}\right)\right) d T(x)+\right. \\
& \left.\int_{T\left(y_{n}\right)}^{1}\left(T(x)-T\left(y_{n}\right)\right) d T(x)\right] .
\end{aligned}
$$

Integrating, we have

$\int_{I}\left(\frac{1}{2}-\min _{i \in N}\left\{\ell\left(y_{i}, x\right)\right\}\right) d x=\left[\frac{1}{2}-\frac{1}{4} \sum \ell\left(y_{i}, y_{i+1}\right)^{2}\right]$. Hence, maximizing $\int_{I}\left(\frac{1}{2}-\min _{i \in N}\left\{\ell\left(y_{i}, x\right)\right\}\right) d x$ is equivalent to minimizing $\sum \ell\left(y_{i}, y_{i+1}\right)^{2}$ by choosing $\left\{y_{1}, y_{2}, \ldots, y_{n}\right\}$ such that $\sum \ell\left(y_{i}, y_{i+1}\right)=1$. This requires $\ell\left(y_{i}, y_{i+1}\right)=\frac{1}{n}$ for all $i$. This implies that the maximized value of $\int_{I}\left(\frac{1}{2}-\min _{i \in N}\left\{\ell\left(y_{i}, x\right)\right\}\right) d x$ equals to $\left[\frac{1}{2}-\frac{1}{4 n}\right]$.

Proof of Proposition 1 Let $|N|>1$. We re-order the charities according to their distance from $x$ in the following way: $\ell\left(y_{n}, x\right) \geq \ell\left(y_{n-1}, x\right) \geq \ldots \geq \ell\left(y_{1}, x\right)$. Notice that there exists a finite number of $x \in I$, where there are multiple orderings that satisfy this condition. In this case, we can arbitrarily pick one of these orderings.

For all games $G^{x}$ where $x \in I$, we define the strategy profile $\zeta_{h}(x)$ implicitly as $i<h$ and $i \in N \Longleftrightarrow f_{i}(x)=s$ for all $h \in N \cup\{n+1\}$. Hence, at the strategy profile $\zeta_{h}(x), Y(x)=\{1,2 \ldots, h-1\}$. Given this notation, if for some $\alpha \leq n, \zeta_{l}(x)$ is not an equilibrium for any $l \leq \alpha$, then it can 
be concluded that at the strategy profile $\zeta_{\alpha}(x)$, charity $\alpha$ is not playing its best response while all preceding charities are. To show the validity of this statement, we use proof by induction to generalize.

For $\alpha=1$, the claim trivially holds. Assume that the argument is true for $\alpha-1$. We show that it is also true for $\alpha$. If for some $\alpha \leq n, l \leq \alpha-1$ implies that $\zeta_{l}(x)$ is not an equilibrium, at the strategy profile $\zeta_{\alpha-1}(x)$ charity $\alpha-1$ is not playing its best response and all preceding charities are. Hence, at the strategy profile $\zeta_{\alpha}(x)$, charity $\alpha-1$ is playing its best response, which implies for all $i \leq \alpha-1$, charity $i$ is playing its best response since $0 \leq \pi_{\alpha-1}\left(y_{a-1}, x,\{1,2 . ., \alpha-1\}\right) \leq$ $\pi\left(y_{i}, x,\{1,2 . ., \alpha-1\}\right)$ for all $i \leq \alpha-1$. If $\zeta_{\alpha}(x)$ is not an equilibrium profile, then there exists a $j$ such that $n \geq j \geq \alpha$ and $\pi_{j}\left(y_{j}, x,\{1,2 . ., \alpha-1\}\right)<\pi_{j}\left(y_{j}, x,\{\{1,2 . ., \alpha-1\} \cup\{j\}\}\right)$. But for any $j \geq \alpha, \pi_{j}\left(y_{j}, x,\{\{1,2 . ., \alpha-1\} \cup\{j\}\}\right) \leq \pi_{\alpha}\left(y_{a}, x,\{\{1,2 . ., \alpha-1\} \cup\{\alpha\}\}\right)$. Hence, if for some $\alpha \leq n$, $l \leq \alpha$ implies that $\zeta_{l}(x)$ is not an equilibrium, then charity $\alpha$ is not playing its best response at the strategy profile $\zeta_{\alpha}(x)$ while all preceding charities are.

Furthermore, if for all $\alpha \leq n, \zeta_{\alpha}(x)$ is not an equilibrium, then $\zeta_{n+1}(x)$ is. For all $\alpha \leq n, \zeta_{\alpha}(x)$ is not an equilibrium implies that $\pi_{n}\left(y_{n}, x,\{1,2 . ., n-1\}\right)=0<\pi_{n}\left(y_{n}, x,\{\{1,2 . ., n-1\} \cup\{n\}\}\right)=$ $\pi_{n}\left(y_{n}, x,\{1,2 . ., n\}\right)$. But $\pi_{n}\left(y_{n}, x,\{1,2 . ., n\}\right) \leq \pi_{i}\left(y_{i}, x,\{1,2 . ., n\}\right)$ holds for all $i \in N$. And when $Y(x)=\{1,2 . ., n\}$ we are at the strategy profile $\zeta_{n+1}(x)$, and as shown none of the charities have a profitable deviation. Therefore, it is an equilibrium profile. Hence, there always exists a pure strategy NE of the game $G^{x}$ for all $x \in I$.

Proof of Proposition 2 Assume that $|N|>1$ and define $S(x)=\left\{i: f_{i}(x)=s\right.$ and $\left.i \in N\right\}$. A strategy profile in which $|S(x)|=0$ cannot be an equilibrium of the game $G^{x}$, since any charity $i$ can increase its payoff to $(g-c)$ by soliciting donations. Proposition 1 implies there exists a pure strategy equilibrium of all games $G^{x}$. Hence, $|S(x)|>0$ for all $x \in I$, which implies that every donor is solicited.

Proof of Proposition 3 The following lemma is required for the proof.

Lemma 2 (i) If $c \geq g / 2$, then almost every donor is solicited exactly once in an equilibrium satisfying $R 1$. (ii) If $c=g / 2$, then almost every donor is solicited by the charity which is ideologically closest to him.

Proof. (i) Define $Z_{0}=\left\{x \in I: \ell\left(y_{i}, x\right)=\ell\left(y_{j}, x\right)\right.$ for some $\left.j, i \in N\right\}$ and $Z=I / Z_{0}$. Note that almost every donor is in $Z$. If $n>2$, then a strategy profile where $|S(x)| \geq 3$ cannot be a Nash Equilibrium (NE) of the game $G^{x}$, since $\sum_{i \in S} g p_{i}\left(y_{i}, x ; Y(x)\right)=g$ implies that there exists 
$j \in S$ such that $g p_{j}\left(y_{j}, x ; Y(x)\right)<g / 2$. If $n \geq 2$, then for all $x \in Z$ a strategy profile that satisfies $|S(x)|=2$ is not a NE of the game $G^{x}$. In order to see this, let $\{n, m\}=S(x)$. Since, $\ell\left(y_{n}, x\right) \neq$ $\ell\left(y_{m}, x\right) \Longrightarrow p_{n}\left(y_{n}, x ; Y(x)\right) \neq p_{m}\left(y_{m}, x ; Y(x)\right)$, which implies that there exists $h \in\{n, m\}$ such that $g p_{h}\left(y_{h}, x ; Y(x)\right)<g / 2$. Hence, by Proposition 1 and $2,|S(x)|=1$ for all $x \in Z$.

(ii) Define $q(x)=\left\{i: \ell\left(y_{i}, x\right)<\ell\left(y_{j}, x\right) \forall j \in N /\{i\}\right\}$, for all $x \in Z$. Then, a strategy profile that satisfies $|S(x)|=1$ and $q(x) \notin S(x)$ is not a NE of the game $G^{x}$, since $\pi_{q(x)}\left(y_{q(x)}, x, S(x)\right)=$ $0<\pi_{q(x)}\left(y_{q(x)}, x,\{S(x) \cup q(x)\}\right)$ implies that $q(x)$ has a profitable deviation.However, for all $x \in Z$, a strategy profile where $S_{1}(x)=\{q(x)\}$ is a NE. In this strategy profile, $q(x)$ cannot improve upon the outcome since $\pi_{q(x)}\left(y_{q(x)}, x, q(x)\right)=g>0$. Furthermore, the remaining charities cannot improve upon the outcome, since for all $i \in N /\{q\}, \pi_{i}\left(y_{i}, x, q(x)\right)=0>\pi_{i}\left(y_{i} . x,\{i, q(x)\}\right)=g p_{i}\left(y_{i}, x ; Y(x)\right)-g / 2$ since $g p_{i}\left(y_{i}, x ; Y(x)\right)<g / 2$. By definition, $q(x)$ is the closest charity to donor $x$ in the ideology space. Hence, $c=g / 2$ implies that in any equilibrium of the game $G$ satisfying $R 1$, almost every donor is solicited only by the charity that is closest to him.

Let $|N|>1$.

(i) Lemma 2 implies that almost every donor is solicited exactly once, hence total net donations are maximized at $(g-c)$.

(ii) Define $\gamma_{i}, y_{i}$ for all $i$ and $r$, as in Appendix B. Define the following strategy profile $\zeta_{k}(x)$ for the game $G^{x}: f_{1}(x)=f_{2}(x)=s$ and $f_{j}(x)=d$, for all $j \in N /\{1,2\}$. Then $\pi_{2}\left(y_{2}, \gamma_{1},\{1,2\}\right)=$ $\pi_{1}\left(y_{1}, \gamma_{1},\{1,2\}\right)=g / 2-c>0$ holds. Since $\pi$ is continuous in $x$ there exists $\varepsilon>0$ such that, whenever $x \in X_{\varepsilon} \equiv\left\{\omega \in I \mid \ell\left(\omega, \gamma_{1}\right) \leq \varepsilon\right\}$

(1) $\pi_{1}\left(y_{1}, x,\{1,2\}\right)>0$ and $\pi_{2}\left(y_{2}, x,\{1,2\}\right)>0$ hold, and

(2) $\ell\left(y_{j}, x\right)>\max \left\{\ell\left(y_{1}, x\right), \ell\left(y_{2}, x\right)\right\}, \forall j \in N /\{1,2\}$.

Then, for all $x \in X_{\varepsilon}$, any strategy profile such that $|S(x)|=1$ is not a NE of the game $G^{x}$. To see this and let $l$ be the only charity soliciting donations from $x$. First, let $l \neq 1$, then $\pi_{1}\left(y_{1}, x, l\right)=0<$ $g p_{1}\left(y_{1}, x,\{1, l\}\right)-c$. If $l=1$, then $\pi_{2}\left(y_{2}, x, 1\right)=0<g p_{2}\left(y_{2}, x,\{1,2\}\right)-c$. Note that the first inequality follows from the properties of the generalized distribution rule. $X_{\varepsilon}$ has a positive measure and $x \in X_{\varepsilon}$ implies that $G^{x}$ does not have an equilibrium in which a single charity solicits $x$. By proposition 1 , there exists a pure strategy NE at all $x \in I$. Therefore, by proposition $2, x \in X_{\varepsilon}$ implies that $G^{x}$ has an equilibrium with $|S(x)| \geq 2$. Hence, there exists excessive fundraising whenever $c<g / 2$.

Proof of Proposition 4 (i) The only part that does not follow from the analysis in section 3.1 is as follows: 
Assuming $V(n)$ is continuous in $n$, the maximizer of this function is $\sqrt{\frac{1}{4 F}}$. But $V(n)$ is concave in this case. Hence, the integers that maximize $V(n)$ are those that are closest to $\sqrt{\frac{1}{4 F}}$. This implies that

$$
n^{*}=\left\{\begin{array}{l}
\{1\} \text { if } \sqrt{\frac{1}{4 F}} \leq 1 \\
n^{m} \text { if } \sqrt{\frac{1}{4 F}}>1
\end{array} .\right.
$$

Formally, let $n_{l}=\sup \left\{Z^{+} \cap\left[0, \sqrt{\frac{1}{4 F}}\right]\right\}$ and $n_{u}=\inf \left\{Z^{+} \cap\left[\sqrt{\frac{1}{4 F}}, \infty\right)\right\}$. Then, we can express $n^{m}$ as a correspondence such that $n^{m}=\underset{n \in\left\{n_{l}, n_{u}\right\}}{\arg \max } V(n)$.

(ii) $F \leq \frac{1}{4}$ implies that $n \geq 2$ for all $n \in n^{*}(F)$.

Proof of Proposition 5 The following Lemmas are required for the proof.

Lemma 3 For any $n$, let $c \geq g / 2$. A strategy profile in which charities solicit donations from almost all donors to whom they are the closest is a NE of the solicitation game.

Proof. Let $q(x)=\left\{i: \ell\left(y_{i}, x\right)<\ell\left(y_{j}, x\right) \forall j \in N /\{i\}\right\}$, for all $x \in Z$. Pick any profile satisfying $S(x)=\{q(x)\}$ for all $x \in Z$. Then for all $x \in Z, \pi_{q(x)}\left(y_{q(x)}, x, q(x)\right)=(g-c)>\pi_{q(x)}\left(y_{q(x)}, x, \emptyset\right)=0$, and $\pi_{i}\left(y_{i}, x, q(x)\right)=0>g p_{i}\left(y_{i}, x,\{q(x), i\}\right)-\frac{g}{2} \geq g p_{i}\left(y_{i}, x,\{q(x), i\}\right)-c$ for all $i \in N /\{q(x)\}$ where the second strict inequality follows from the properties of the general allocation rule. Therefore, no charity has a profitable deviation from this strategy profile.

Lemma 4 When $c \geq g / 2$, there always exists a SPNE in which every charity solicits those donors, for whom they are the closest charity.

Proof. Define $n^{h} \equiv \sup \left\{Z^{+} \cap\{x \mid x \leq \bar{n}\right.$ and $\left.x \in R\}\right\}$. Consider the profile where only $n^{h}$ charities, which are $1 / n^{h}$ apart from each other, enter in the first stage. Furthermore, assume that every charity has a strategy of soliciting only those donors to whom they are the closest charity, whenever they enter the game. By Lemma 3, this strategy profile generates a NE in every possible sub-game. In particular, in a sub-game where only $n^{h}$ charities that are $1 / n^{h}$ apart from each other enter in the first stage, this strategy profile constitutes a NE of the solicitation game.

In this strategy profile, $n^{h} \leq \bar{n}$ implies that $\phi_{i} \geq 0$. Hence, the $n^{h}$ charities do not have a profitable deviation in the first round. Furthermore, given the strategies of every other charity, charities that have not entered in the first round, do not have a profitable deviation from not entering. Assume that a new charity enters the market. Given the strategies of the $n^{h}$ charities, its best response is to 
solicit donors that are closest to its ideology, which generates a payoff of $\frac{1}{2 n^{h}}(g-c)$. Therefore, for entrance to be profitable $\frac{1}{2 n^{h}}(g-c)>F$ must hold. But by definition, $F=(g-c) / \bar{n}$. Hence, we have $\bar{n}>2 n^{h}$. Again by definition, $n^{h}+1>\bar{n}$. Combining the two inequalities, we must have $n^{h}<1$, which is a contradiction with our assumption that $\bar{n}>n^{*}>1$. Hence, there cannot be any profitable deviation for charities that do not enter in this strategy profile. Therefore, this strategy profile is a SPNE.

(i) Follows immediately from propositions 3 and 4 .

(ii) Let $n^{k}$ denote the greatest element of $n^{*}$ (if $n^{*}$ is singleton, $n^{k}$ is its only element) and assume $n^{k} \geq 3$. If $n^{k}=2$, the proof can be trivially extended to that case as well. And let $n^{h}$ be the same number as in Lemma 4. If $n^{k} \neq n^{h}$, then by Lemma 4, there are other SPNE that are inefficient. If $n^{k}=n^{h}$, then there exists $\varepsilon>0$ such that a profile in which $n^{k}$ charities for which $\ell\left(y_{i}, y_{i+1}\right)=1 / n^{k}$ for all $i \in\left\{2, \ldots, n^{k}\right\}, \ell\left(y_{n^{k}}, y_{1}\right)=\frac{1}{n^{k}}-2 \varepsilon$ and $\ell\left(y_{1}, y_{2}\right)=\frac{1}{n^{k}}+2 \varepsilon$ is satisfied enter in the first stage and every charity's strategy is to solicit only those donors to whom they are the closest whenever they enter in the first stage, is a SPNE.

In order to verify the validity of this claim, first note that by Lemma 3 this strategy profile constitutes a NE at any possible sub-game. Next, notice that $\phi_{n^{k}}=\left(\frac{1}{n^{k}}-\varepsilon\right)(g-c)-F$ and that there exists $\varepsilon>0$ such that $\phi_{n^{k}}>0$ since $n^{k}<\bar{n}$. Furthermore, $\phi_{n^{k}}<\phi_{i}$ for all $i \in\left\{1,2, \ldots, n^{k}-1\right\}$. Hence, none of the charities that have entered in the first stage have a profitable deviation by not entering. Finally, by a similar argument as in Lemma 4, observe that charities that have not entered in the first stage do not have a profitable deviation in the first stage by entering. Since in this strategy profile all charities are not equidistant from each other, there always exists inefficient SPNE of this game.

Proof of Proposition 6 Let $n$ denote the smallest element of $n^{*}$. Let $\Gamma_{i}$ be the proportion of donors solicited by charity $i$, than $\sum_{i \in N} \Gamma_{i}=\Gamma$, is the measure of solicitations made. Note that each donor donates $g$ whenever she is solicited, regardless of the number of solicitations that she received. Therefore,

$$
\sum_{i \in N} \phi_{i} \leq\left\{\begin{array}{c}
\Gamma\left(g-c_{o}\right)-\sum_{i \in N} E_{i} \text { if } \Gamma<1 \\
g-\Gamma c_{o}-\sum_{i \in N} E_{i} \text { if } \Gamma \geq 1
\end{array} .\right.
$$

Hence, $\Gamma<1$ implies

$$
\sum_{i \in N} \phi_{i} \leq \Gamma\left(g-c_{o}\right)-\sum_{i \in N} E_{i}=\Gamma\left(g-c_{o}\right)-n F-\Gamma\left(c-c_{o}\right)=\Gamma(g-c)-n F<(g-c)-n F .
$$


Where the first equality is obtained by imposing the no outside financial sources constraint.

Therefore, $(g-c)-F n>\sum_{i \in N} \phi_{i}$ has to be satisfied. However, by assumption $(g-c) / F=\bar{n}<n$.

Hence, $0>(g-c)-F n>\sum_{i \in N} \phi_{i}$, a contradiction with the SPNE requirement that $\phi_{i} \geq 0$ for all $i$.

$\Gamma \geq 1$ implies

$$
\sum_{i \in N} \phi_{i} \leq g-\Gamma c_{o}-\sum_{i \in N} E_{i}=g-\Gamma c_{o}-n F-\Gamma\left(c-c_{o}\right)=g-\Gamma c-n F \leq(g-c)-F n .
$$

Where the first equality is obtained by imposing the no outside financial sources constraint.

Hence, $(g-c)-F n \geq \sum_{i \in N} \phi_{i}$. This condition together with $(g-c) / F=\bar{n}<n$ implies that $0>(g-c)-F n>\sum_{i \in N} \phi_{i}$. Therefore, in SPNE, $n \leq \bar{n}$ has to be satisfied.

Proof of Proposition 7 The strategy profile where every charity accepts the offer in Step 3 and solicits only those donors, for whom it is the closest charity in any sub-game, is the only type of SPNE and is efficient. First, observe that by Lemma 2, this strategy profile constitutes the only NE of the solicitation game. Second, observe that this results in $\phi_{i}>0$ for all $i$. Hence, no charity has a profitable deviation in the first round and this profile is indeed a SPNE. By Proposition 4, it is also efficient.

To check that every SPNE is of this form, observe that by Lemma 2, the strategy profiles where charities solicit only those donors, for whom they are the closest charity, is the only NE of the solicitation game. Hence, in any SPNE, every charity must be playing these strategies at every subgame and if there is a different type of SPNE of this game, it must be the one where only a subset of the charities to whom an offer has been extended to, accept the offers. But, this implies that those not entering in the first round have a profitable deviation. In every sub-game of the game, each charity solicits only those donors for whom it is the closest charity. Given this behavior of other charities, those that have not entered would generate a positive payoff from entering and soliciting those donors to whom they are the closest charity (they would simply reach our efficient SPNE). In such SPNE, the no-outside borrowing constraint is trivially met.

\section{References}

[1] Andreoni, J., 1998, Toward a theory of charitable fundraising, Journal of Political Economy, 106, $1186-1213$. 
[2] Andreoni, J. and A.A. Payne, 2003, Do government grants to private charities crowd out giving or fundraising?, American Economic Review, 93, 792-812.

[3] Andreoni, J., 2006a, Philanthropy, Handbook of Giving, Reciprocity and Altruism, S-C. Kolm and J. Mercier Ythier, eds., Amsterdam, North Holland, 1201-1269.

[4] Andreoni, J., 2006b, Leadership giving in charitable fundraising, Journal of Public Economic Theory, 8, 1-22.

[5] Bilodeau, M. and A. Slivinski, 1997, Rival charities, Journal of Public Economics, 66, 449-467.

[6] Bradley, B., P. Jansen, and L. Silverman, 2003, The non-profit sector's $\$ 100$ billion opportunity, Harvard Business Review, 81, 94-108.

[7] Chua, V.C.H. and C.M. Wong, 2003, The role of united charities in fundraising: The case of Singapore, Annals of Public and Cooperative Economics, 74, 433-464.

[8] d'Aspremont, C., J.J. Gabszewicz, and J.F. Thisse, On Hotelling's "Stability in Competition", Econometrica, 47, 1145-1150.

[9] Duncan, B., 2002, Pumpkin pies and public goods: The raffle fundraising strategy, Public Choice, $111,49-71$.

[10] Economides, N. and S. Rose-Ackerman, 1993, Differentiated Public Goods: Privatization and Optimality, in Does Economic Space Matter? Essays in Honour of Melvin L. Greenhut, edited by H. Ohta \& J.-F. Thisse. St. Martin's Press, NY.

[11] Fisher, F.M, 1977, On donor sovereignty and united charities, American Economic Review, 67, 632-638.

[12] Glazer, A. and A.K. Konrad, 1996, A signalling explanation for charity, American Economic Review, 86, 1019-1028.

[13] Harbaugh, W.T., 1998, What do donations buy? A model of philanthropy based on prestige and warm glow, Journal of Public Economics, 67, 269-284.

[14] Hotelling, H., 1929, Stability in competition, Economic Journal, 39, 41-57. 
[15] Jacobs, F. and N. Marudas (2006), Excessive, optimal, and insufficient fundraising among the Nonprofit Times 100, International Journal of Nonprofit and Voluntary Sector Marketing, 11, 105-114.

[16] Khanna, J., Posnett, J. and T. Sandler, 1995, Charity donations in the UK: New evidence based on panel data, Journal of Public Economics, 56, 257-272.

[17] Okten, C. and B.A. Weisbrod, 2000, Determinants of donations in private nonprofit markets, Journal of Public Economics, 75, 255-272.

[18] Romano, R. and H. Yildirim, 2001, Why charities announce donations: A positive perspective, Journal of Public Economics, 81, 423-447.

[19] Rose-Ackerman, S., 1982, Charitable giving and 'excessive' fundraising, Quarterly Journal of Economics, 97, 193-212.

[20] Schervish, P.G. and J.J. Havens, 1997, Social participation and charitable giving: A multivariate analysis, Voluntas: International Journal of Voluntary and Nonprofit Organizations, 8, 235-260.

[21] Vesterlund, L.D., 2003, The informational value of sequential fundraising, Journal of Public Economics, 19, 131-138.

[22] Yörük, B.K., 2009, How responsive are charitable donors to requests to give?, Journal of Public Economics, 93, 1111-1117. 
Figure 1. Ideology spaces

A. Unit circle

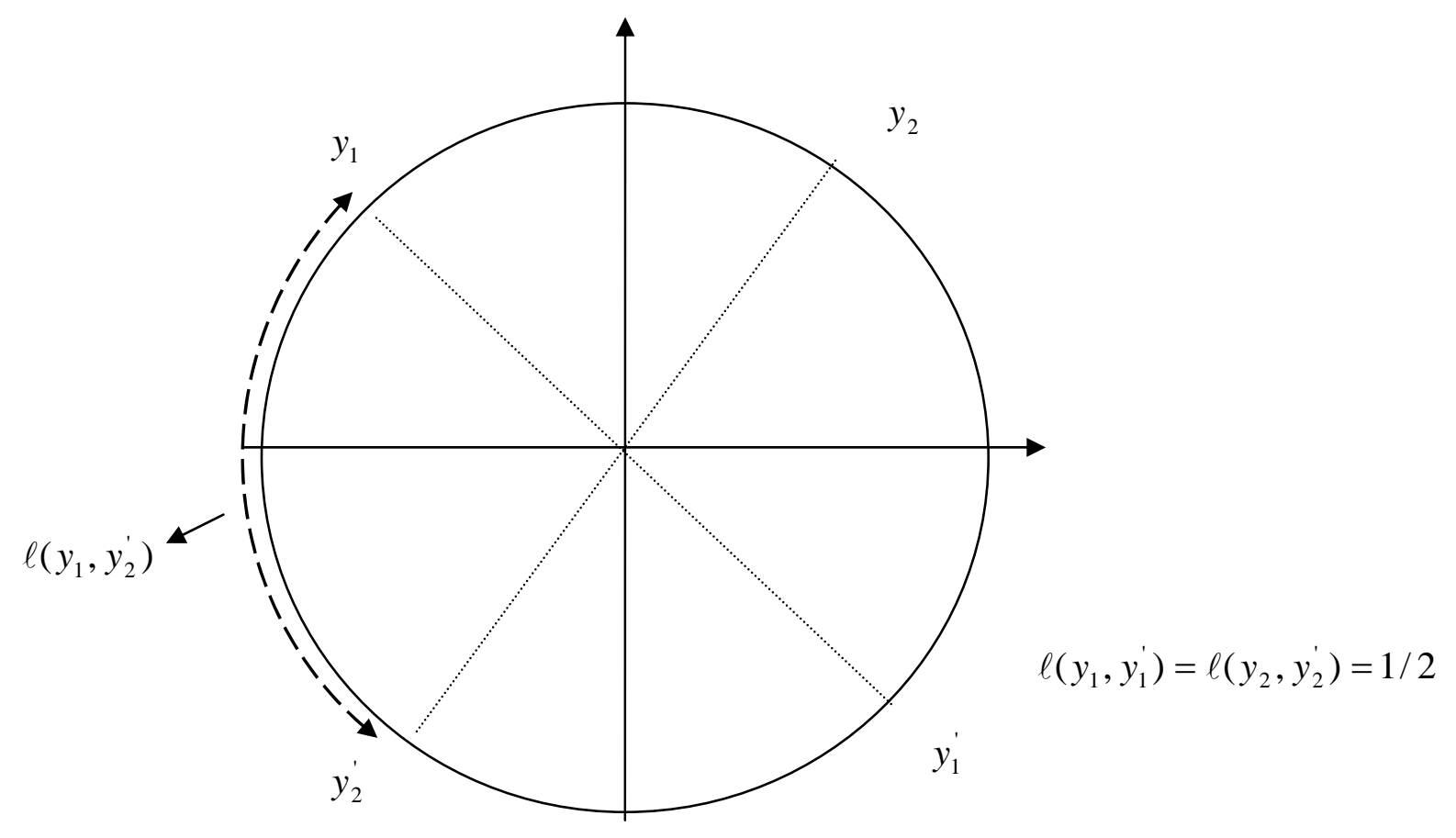

B. Unit interval

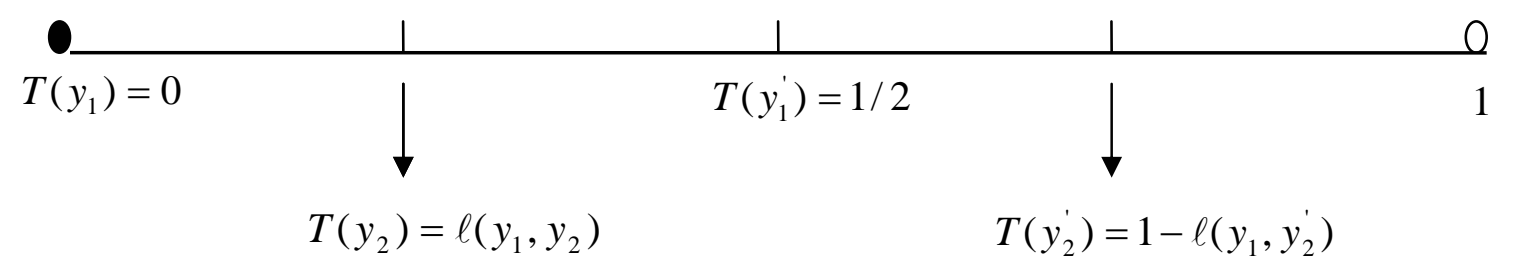


Figure 2. Returns to solicitations for two charities

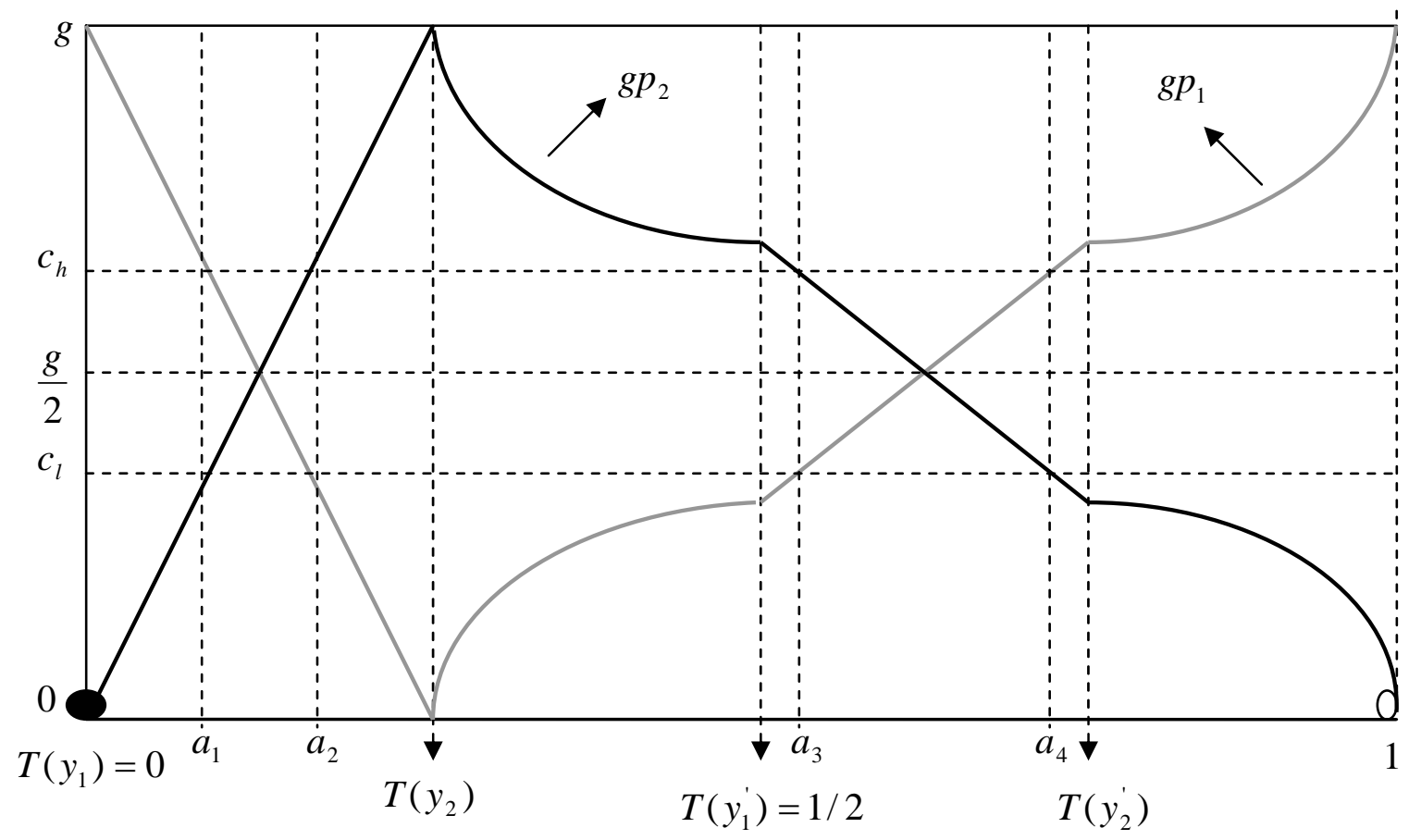

